\title{
Transhemispheric Disparities In The General Knowledge Of Business Majors: By Major Population Segments
}

Richard Scott, (scottr@mscd.edu), Metropolitan State College of Denver Judith Scott, (scottj@mscd.edu), Metropolitan State College of Denver

Norm Pence, (pencen@mscd.edu), Metropolitan State College of Denver

\begin{abstract}
A 100-question general knowledge test was constructed and administered to 284 senior business administration majors in the USA and South Africa. The test consisted of two major components, Liberal Arts and Business Administration. Within Liberal Arts, five subcomponents were tested: current affairs, history, geography, literature/fine arts and mathematics/science. Similarly, in Business Administration five subcomponents were tested: accounting, economics, finance, management and marketing. Along with demographic information, means of individual test scores were calculated and the data set was further cross-tabulated in order to test for statistical significance. The researchers address a topic that few would tackle in today's climate of hypersensitivity to suggestions of disparities that may exist among major population segments, even if the differences are in general knowledge, not ability. The study details findings in Liberal Arts and Business Administration and contrasts the results.
\end{abstract}

\section{Introduction}

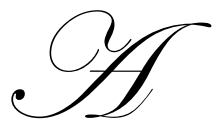

merica has often been referred to as a nation of immigrants and a "melting pot" where disparate cultures blend into one. Such blending assumes that over time differing cultural groups start to look like one another with respect to their economic and political prowess and the knowledge they possess. One would have to be comatose not to recognize that there still exists in today's America a significant difference in the economic potency and political clout possessed by the white majority as contrasted to the black minority component of the population.

In the end, of course, knowledge means power. So, it should not be a great surprise to learn that throughout history dominant groups have tried hard to keep subordinate groups from possessing it. For example, during the period of American slavery, Blacks were not allowed to learn to read, the first tool of knowledge. Similarly, colonial powers limited the education of its colonies' native born. Colonial powers, like slave masters, recognized that knowledge carries with it a sense of who the group is -- their culture -- and gives them the promise of a future that will be different from the present. Knowledge, therefore, gives those who possess it the understanding of their culture and the tools that will get them from here to there. Furthermore, one of the time-honored conceptions of teaching is recognized as the transmission of cultural knowledge.

America has progressed from a time where knowledge was withheld from minorities. Now, cutting across all of America's population segments, educational excellence has become a primary goal of American educators and policymakers. During the 1990s, for example, educational reform and increased expectations for all students to achieve their highest potential have been the hallmark of national and state policies and programs (Campbell, Voelkl

Readers with comments or questions are encouraged to contact the authors via email. 
\& Donahue, 1997). Part of the rationale for the pursuit of high academic achievement is because the modern economy needs knowledgeable workers. In fact, the hue and cry of the business world is for an educational system that emphasizes the development of analytical skills and problem-solving abilities. Further, the common practice of using affirmative action plans to achieve a balanced workforce (both in absolute numbers and in their skills disposition) infers that there is a counterbalance in the knowledge that employees bring to the workplace.

This begs the question: do American Whites and American Blacks possess the same knowledge? It is important to define how the word "knowledge" is used here. It is defined as "The state or fact of knowing; familiarity, awareness, or understanding gained through experience or study; that which is known; the sum or range of what has been perceived, discovered, or inferred; specific information about something" (The American Heritage Dictionary, 1976). Armed with this definition the reader should conclude that the authors are not addressing intellectual capabilities but rather the information that is possessed by each population segment gleaned through experience or study.

\section{The Knowledge Deficit}

Considerable evidence exists in extant literature that answers the question in this way - on the whole, as contrasted to American Whites, Blacks have a knowledge deficit. For example, in their book published by the Brookings Institution, Jencks and Phillips (1998) note that Blacks score lower than Whites on tests that purport to measure specific knowledge and/or scholastic aptitude. They maintain that this knowledge gap "appears before children enter kindergarten, and it persists into adulthood." According to Jencks and Phillips, the typical American Black score below 75 percent of American Whites on most standardized tests and on some tests, Blacks score below more than 85 percent of Whites. Jencks and Phillips argue that "reducing the Black-White test score gap would reduce racial disparities in educational attainment as well as in [lifetime] earnings." Jencks and Phillips maintain that the knowledge gap is caused by a combination of culture and schooling.

While it is unclear what truly causes the knowledge gap between American Blacks and Whites, it is believed that most scholars who study the mean scores achieved by these two racial groups recognize that it exists. Whether caused by cultural differences, unequal schooling, income inequality, work ethic, family make-up, community environment, or whatever; the knowledge gap exists according to published data in: reading, geography, history, mathematics, science, advanced placement examinations, SAT and ACT test results, to name a few. In each of these aforementioned areas, data gleaned from recent studies is summarized below.

\section{Reading}

The knowledge deficit of American Blacks may be due, in part, to reading deficiency. A student's ability to read is essential to the educational process. If students fall behind in reading proficiency, they may find it difficult to benefit from other aspects of the curriculum. In the future, poor readers may also find it difficult to participate effectively in an economy requiring increasingly sophisticated job skills. Table 1 shows the gap in reading proficiency between American Whites and Blacks at three grade levels (Grade 4, Grade 8, and Grade 12). Further, although not shown in Table 1, every racial/ethnic group (White, Hispanic, Asian/Pacific Islander, American Indian, and Alaskan Native) scored higher than Blacks in terms of their average reading proficiency scores.

\section{Geography}

Consider geography proficiency as another example of the knowledge gap between American whites and blacks. Most people would agree that to be able to compete in today's global economy, students require not just a familiarity with globes, atlases, and maps, but also the knowledge to fully understand these items and the skills necessary to put that knowledge into practice. The National Assessment of Educational Progress sought to measure the geographic proficiency of American students in the $4^{\text {th }}, 8^{\text {th }}$-, and $12^{\text {th }}$-grades. The findings of the study revealed that 
White students outscored ${ }^{1}$ Black students (The Condition of Education -- Indicator 19, 1996).

Table 1

Average Reading Proficiency Scores, by Race, 1998

\begin{tabular}{|l|c|c|c|}
\hline Race & Grade 4 & Grade 8 & Grade 12 \\
\hline \hline White & 227 & 272 & 298 \\
\hline Black & 194 & 243 & 270 \\
\hline
\end{tabular}

Source: Data extracted from U.S. Department of Education, National Center for Education Statistics, NAEP 1998 Reading, A Report Card for the Nation and the States, 1999.

\section{History}

Further evidence is gleaned from knowledge of history. A working knowledge of history - the country's struggles, and failings - allows citizens to make informed and intelligent decisions about contemporary issues. There has recently been a renewed interest in the role of history in education, prompting the National Education Goals Panel to include history on its list of key subjects to assess. The results of this assessment revealed that the average history proficiency scores of Whites were higher ${ }^{2}$ than those of Blacks in grades 4, 8, and 12 (The Condition of Education -- Indicator 18, 1996).

\section{Mathematics}

Proficiency in mathematics is an important outcome of education. In addition, knowledge of mathematics is critical for success in science, computing, and a number of other related fields of study. In an increasingly technological world, the mathematics skills of American workers may be a crucial component of economic competitiveness. Table 2 shows that for three grade levels (Grade 4, Grade 8, and Grade 12 the mathematics proficiency of Whites is greater than for Blacks. Although not shown in Table 2, every racial or ethnic group (White, Hispanic, Asian/Pacific Islander, American Indian, and Alaskan Native) scored higher than Blacks in average mathematics proficiency.

Table 2

Average Mathematics Proficiency Scores, by Race, 1996

\begin{tabular}{||l|c|c|c||}
\hline \hline Race & Grade 4 & Grade 8 & Grade 12 \\
\hline \hline White & 232 & 282 & 311 \\
\hline Black & 200 & 243 & 280 \\
\hline
\end{tabular}

Source: Data extracted from U.S. Department of Education, National Center for Education Statistics, NAEP 1996 Mathematics Report Card for the Nation and the States: Findings from the National Assessment of Educational Progress, 1997.

\section{Science}

With respect to general science knowledge, Blacks also lag behind Whites. This is shown by performance data released by the National Assessment of Educational Progress science assessment which was gleaned by two methods: conventional multiple choice examination and performing "hands-on tasks." At all grade levels evaluated $\left(4^{\text {th }}-, 8^{\text {th }}-\right.$ and $12^{\text {th }}$-grade $)$ and for both methods employed, White students outperformed their Black counterparts (National Assessment Governing Board Science Performance Standards, 1996).

\section{Advanced Placement Examinations}

Another source that underscores the differing performance level of Whites and Blacks is taken from data concerning Advanced Placement (AP) examinations. Participation in the AP program is associated with a demanding academic curriculum and illustrates the desire of schools, colleges, and universities to offer college-level courses in high school. By participating in the AP program, high school students may acquire college credit for their knowledge of college-level subjects. Students scoring 3 or higher on an AP examinations usually receive college credit.

\footnotetext{
${ }^{1}$ Average scores were 218 to 168 for $4^{\text {th }}$-grade; 270 to 229 for $8^{\text {th }}$-grade; and 291 to 258 for 12 th-graders.

${ }^{2}$ Average scores were 215 to 177 for $4^{\text {th }}$-grade; 267 to 239 for $8^{\text {th }}$-grade; and 292 to 265 for 12 th-graders.
} 
Table 3 shows the number of examinations with scores of 3 or higher (per 1,000 $12^{\text {th }}$-grade students) by subject area and race/ethnicity. Clearly, with respect to AP examinations, the data contained in Table 3 shows that: (1) proportionally, considerably more White students take Advanced Placement examinations than do their Black contemporaries; and, (2) significantly more Whites outperform Blacks on the AP examinations, and thus, receive more college credits while still in high school as a result of the scores achieved on these exams. Further, although not depicted in Table 3, Hispanics also scored higher than their Black counterparts. The number of AP examinations with scores of 3 or higher were not available for other racial/ethnic groups.

Table 3

Advanced Placement Examinations, 1996

(By number of AP exams taken / number of scores of 3 or higher per $1,00012^{\text {th }}$-Graders)

\begin{tabular}{||l|c|c|c|c|c|c||}
\hline $\begin{array}{c}\text { Race or Eth- } \\
\text { nicity }\end{array}$ & Social Studies & English & $\begin{array}{c}\text { Foreign Lan- } \\
\text { guage }\end{array}$ & Calculus & $\begin{array}{c}\text { Computer Sci- } \\
\text { ence }\end{array}$ & Science \\
\hline \hline White & $60 / 37$ & $59 / 40$ & 36718 & $33 / 21$ & 36527 & $34 / 21$ \\
\hline Black & 36658 & 36660 & 36527 & 36561 & 0 & 36562 \\
\hline
\end{tabular}

Source: Data extracted from The College Board, Advanced Placement Program, National Summary Reports, various years, 1996. Note: To read Table 3, the number on the left of the slash mark in each column represents the number of AP exams taken and the number to the right of the slash mark depicts the number of scores of 3 or higher achieved by each $1,00012^{\text {th }}$ grade students.

\section{National Scholastic Assessment Test (SAT)}

Further evidence of the knowledge disparity between White and Black students can be gleaned in reviewing Scholastic Assessment Test (SAT) scores. The SAT is the test taken most frequently by college-bound students. It is designed to predict success in the freshmen year of college, and to track the performance of groups of students who intend to enter college over time. The SAT test scores are divided into three parts: verbal, mathematics and combined score. Available data show that at least for the past twenty years White SAT scores were significantly higher than Black scores (The Condition of Education, Supplemental Table 22-2, 1996). Table 4 shows the 1999 mean SAT scores for Whites and Blacks with respect to their verbal, math, and combined scores. Although the data is not included in Table 4, every racial/ethnic group (White, American Indian/Alaskan Native, Asian, Asian American/Pacific Islander/Mexican/Mexican American, Puerto Rican, and Other Latino) scored higher than Blacks on each component of the SAT.

Table 4

Mean SAT Scores, by Race, 1999

\begin{tabular}{|l|c|c|c|}
\hline Race & Verbal & Math & Combined \\
\hline White & 527 & 528 & 1055 \\
\hline Black & 434 & 422 & 856 \\
\hline
\end{tabular}

Source: Data extracted from 1999 Profile of College-Bound Seniors -- National Report, The College Board, 1999.

\section{National ACT Standardized Test}

Like the SAT test, the ACT Assessment is designed for students who plan to attend college. Table 5 consists of data based on all high school graduates of the class of 2000 who took the ACT Assessment during their sophomore, junior, or senior year. For students who took the test more than once, on the most recent scores are used. Table 5 was constructed from the ACT Assessment of 470,451 White students and 63,837 Black students. As can be determined by the data in Table 5, Whites outperformed their Black counterparts. Although the table does not reflect other racial/ethnic group comparisons, data from the sourced reference shows that all racial/ethnic groups (Whites, American Indians, Mexican-Americans, Asian-Americans, and Puerto Rican/Hispanics) outperformed 
Blacks in every subject listed in Table 5.

Table 5

Average ACT Assessment Scores, by Core Subject and Race

\begin{tabular}{|l|c|c||}
\hline \multicolumn{1}{|c|}{ Core Subject } & White & Black \\
\hline \hline English & 22.3 & 8.6 \\
\hline Usage/Mech & 11.3 & 8.9 \\
\hline Rhet Skills & 11.5 & 17.6 \\
\hline Mathematics & 22.4 & 8.9 \\
\hline Pre/Elem-Alg & 12 & 8.6 \\
\hline Alg/Crd-Geom & 11 & 8.7 \\
\hline Plane Geom/Trig & 11.5 & 17.8 \\
\hline Reading & 23.1 & 8.6 \\
\hline Soc Stu/Sci & 11.7 & 9.2 \\
\hline Arts/Literature & 12 & 17.9 \\
\hline Sci Reasoning & 22.5 & 17.8 \\
\hline Composite & 22.7 & \\
\hline
\end{tabular}

Source: Data extracted from ACT Media Relations, 2000 ACT National and State Scores: Selections from the 2000 National Score Report, 2000.

\section{Purpose Of The Study}

Given the foregoing research outlined in the Introduction detailing evidence that there appears to be a knowledge gap between American Whites and Blacks -- at least in those areas cited -- one may wonder how both population segments compare to similarly-situated population segments in another country. While there are published international assessments of U.S. students with students of other nations in elementary, mid-school and secondary school, there are no known studies that compare the general knowledge of higher education students either in terms of liberal arts-type knowledge or the knowledge gleaned from the intense study of a particular college or university major. Thus, this study was designed to accomplish all of these tasks: (1) compare Whites and Blacks enrolled in higher education in the U.S. and another nation; and, (2) compare them with regard to their knowledge of liberal arts and a specialized course of study.

\section{Choice Of Country To Be Contrasted With U.S.}

In many aspects, the Republic of South Africa and the U.S. have similar histories. For example, they were discovered and populated by Europeans, and at about the same time, expanded their bases into the continent where they were located, seized land from the native inhabitants, fought against British colonization, and established policies of White domination and formulated legal and social doctrines that undermined the freedoms of some components of their populations. Given such similarities, although geographically hemispheres apart, the researchers of this study felt that it was appropriate to use these two countries - the U.S. and South Africa - to contrast the findings of the general knowledge of the major population segments in these two countries.

\section{Research Methods}

\section{General Knowledge Test Instrument Development}

Working as a team, researchers from the United States (USA) and the Republic of South Africa (RSA) constructed a General Knowledge Test (GKT) to be administered near-simultaneously during late-1995 and early-1996 to senior business administration majors in the USA and the RSA. Before taking the test, the participants completed 
a set of demographic characterizations: gender, age, ethnicity, academic major and whether they completed high school in a public or private institution.

The GKT consisted of 100 questions and the questions were evenly divided between two major parts, Liberal Arts and Business. Fifty questions each were in the Liberal Arts component and fifty questions in the Business component. The Liberal Arts section comprised ten questions each in five subjects: current affairs, history, geography, literature/arts and math/science. The Business component consisted of ten questions in five subject areas: accounting, economics, finance, management and marketing.

Within each of the two major test sections a considerable effort was expended to remove geographical bias from the questions posed. The researchers creating the test instrument were aware that every person who develops questions for a general knowledge test would likely choose a different set of questions for that purpose. In fact, the possible combinations and permutations for a 100-question general knowledge test are almost endless. But decisions have to be made -- otherwise a study of this sort will get stymied by paralysis by analysis.

\section{The Populations Studied}

The population for this study was selected for convenience as one of the researchers for this study was onassignment to the RSA as a J. William Fulbright Scholar to Rhodes University in Grahamstown, South Africa. Senior business administration students in the USA and RSA were targeted as the subjects in the study. Both of these groups were at the end of their undergraduate studies. Both groups were enrolled in the capstone course in business administration, Strategic Management. Interestingly, although hemispheres apart, both groups were taking the course using the same textbook (Thompson/Strickland, Strategic Management: Text and Cases, $8^{\text {th }}$ edition, 1995, Irwin Publishing Company). Both country groups had already taken their requisite business foundation courses in accounting, economics, finance, management and marketing.

Taking the GKT were 107 RSA students and 177 USA students, or a total of 284 students from both countries. The ethnicity of these students was self-reported to be: 36 Blacks (27 RSA and 9 USA), 204 Whites (RSA 67 and 137 USA) and 44 other (most Other respondents self-reported themselves as Hispanic in the USA and as Coloureds (mixed blood) in RSA.) The average age of both student groups was 24.65 years with the RSA students being slightly younger than their USA counterparts. Two motivational incentives were offered to each country group in an attempt to get them to do their best on the test. The first incentive was to appeal to their competitive zeal by explaining that their test results were going to be contrasted with students from another country. The second motivation was monetary. Thus, a money incentive was offered and given to the student in each country achieving the highest score.

\section{Delimitations of the Study}

Almost all empirical research has boundaries that limit their scope. This study also has a few_delimiting factors: geographic regions studied, composition and size of the sample, appropriateness of the general knowledge test and other factors that the reader may consider. These boundaries, however, should not be so causal such that empirical research is restrained - otherwise, the research undertaken would become a very small fraction of the useful studies now extant.

\section{Null Hypotheses Tested}

$\mathrm{Ho}_{1}$ : the population means of RSA Blacks and RSA Whites are equal $\left(\mu_{\mathrm{RSA}-\mathrm{Blacks}}=\mu_{\mathrm{RSA} \text {-Whites }}\right)$.

$\mathrm{Ho}_{2}$ : the population means of USA Blacks and USA Whites are equal ( $\left.\mu_{\text {USA-Blacks }}=\mu_{\text {USA-Whites }}\right)$.

$\mathrm{Ho}_{3}$ : the population means of Blacks and Whites are equal $\left(\mu_{\text {Blacks }}=\mu_{\text {Whites }}\right)$. 


\section{Statistical Treatment of the Data Set}

Each individual test was scored and the results plus the demographic information was compiled and treated by a Statgraphics program in South Africa. Then the data set was forwarded to the USA where it was further treated with SPSS, Version 8.0. These statistical treatments yielded descriptive statistics including means and standard deviations with accompanying histograms. Additionally, cross tabulations were accomplished with resulting chisquares. Then, the Student's t-Test values and p-Values were calculated and finally, the Levene's Test for Equality of Variances provided a plethora of possibilities to study.

\section{Findings}

Knowledge of Liberal Arts Subjects

Table 6 shows that RSA Blacks scored significantly better than the RSA Whites in Current Affairs. The RSA Whites, however, scored significantly better than the RSA Blacks in Literature/Fine Arts and Math/Science. There were no significant differences noted in Geography and History.

Table 6

Liberal Arts Knowledge -- RSA Blacks and RSA Whites

\begin{tabular}{|l|c|c|c|c|c|}
\cline { 2 - 6 } \multicolumn{1}{c|}{} & \multicolumn{2}{c|}{ RSA Blacks } & \multicolumn{2}{c|}{ RSA Whites } & p-Value \\
\hline $\begin{array}{c}\text { Liberal Arts Sub- } \\
\text { jects }\end{array}$ & $\begin{array}{c}\text { Sample } \\
\text { Mean }\end{array}$ & $\begin{array}{c}\text { Standard } \\
\text { Deviation }\end{array}$ & Sample Mean & $\begin{array}{c}\text { Standard } \\
\text { Deviation }\end{array}$ & $.018^{* *}$ \\
\hline Current Affairs & 6.85 & 2.14 & 5.7 & 2.07 & $.253^{*}$ \\
\hline Geography & 4.74 & 1.91 & 5.24 & 1.89 & $.200^{*}$ \\
\hline History & 4.67 & 1.71 & 5.21 & 1.9 & $.010^{* *}$ \\
\hline Literature/Fine Arts & 4.37 & 1.8 & 5.42 & 1.73 & $.003^{* *}$ \\
\hline Math/Science & 6.11 & 1.65 & 7.22 & 1.56 & \\
\hline
\end{tabular}

* Cannot Reject $\mathrm{Ho}_{1} @ \square=.05$ level.

** Reject $\mathrm{Ho}_{1} @ \square=.05$ level

Table 7 shows that USA Whites scored significantly better than the USA Blacks in Geography and Math/Science. There was no significant difference, however, in the liberal arts areas of Current Affairs, History, and Literature/Fine Arts.

Table 7

Liberal Arts Knowledge - USA Blacks and USA Whites

\begin{tabular}{|c|c|c|c|c|c|}
\hline & \multicolumn{2}{|c|}{ USA Blacks } & \multicolumn{2}{|c|}{ USA Whites } & \multirow[b]{2}{*}{ p-Value } \\
\hline $\begin{array}{c}\text { Liberal Arts Sub- } \\
\text { jects }\end{array}$ & $\begin{array}{c}\text { Sample } \\
\text { Mean }\end{array}$ & $\begin{array}{l}\text { Standard } \\
\text { Deviation }\end{array}$ & $\begin{array}{c}\text { Sample } \\
\text { Mean }\end{array}$ & $\begin{array}{l}\text { Standard } \\
\text { Deviation }\end{array}$ & \\
\hline Current Affairs & 4.11 & 2.03 & 4.89 & 1.93 & $243^{*}$ \\
\hline Geography & 3.22 & 1.3 & 4.37 & 1.71 & $.049 * *$ \\
\hline History & 5.11 & 2.03 & 4.6 & 1.75 & $.400^{*}$ \\
\hline Literature/Fine Arts & 4.00 & 2.24 & 5.12 & 1.94 & $.099 *$ \\
\hline Math/Science & 5.78 & 2.39 & 7.04 & 1.82 & $.050 * *$ \\
\hline
\end{tabular}

* Cannot Reject $\mathrm{Ho}_{2} @ \square=.05$ level.

**Reject $\mathrm{Ho}_{2} @ \square=.05$ level

Table 8 depicts the statistics derived when combining the scores achieved on the Liberal Arts portion of the General Knowledge Test by all Black participants in the research from both the USA and RSA and then contrasting them with the Liberal Arts scores achieved by all White participants from both countries. As noted in Table 8, the 
Black participants scored significantly better than the Whites in Current Affairs. The Whites, however, scored significant better in Literature/Fine Arts and Math/Science. There were no significant differences in Geography and History.

Table 8

Liberal Arts Knowledge -- Contrasting the Combination of RSA and USA Blacks With the Combination of RSA and USA Whites

\begin{tabular}{|l|c|c|c|c|c|}
\cline { 2 - 5 } \multicolumn{1}{c|}{} & \multicolumn{2}{c|}{$\begin{array}{c}\text { Combination of } \\
\text { RSA and USA Blacks }\end{array}$} & \multicolumn{2}{c|}{$\begin{array}{c}\text { Combination of } \\
\text { RSA and USA Whites }\end{array}$} & p-Value \\
\hline $\begin{array}{c}\text { Liberal Arts Sub- } \\
\text { jects }\end{array}$ & $\begin{array}{c}\text { Sample } \\
\text { Mean }\end{array}$ & $\begin{array}{c}\text { Standard } \\
\text { Deviation }\end{array}$ & Sample Mean & $\begin{array}{c}\text { Standard } \\
\text { Deviation }\end{array}$ & $.007^{* *}$ \\
\hline Current Affairs & 6.17 & 2.41 & 5.16 & 2.01 & $.370^{*}$ \\
\hline Geography & 4.36 & 1.88 & 4.66 & 1.81 & $.948^{*}$ \\
\hline History & 4.78 & 1.77 & 4.8 & 1.82 & $.006^{* *}$ \\
\hline Literature/Fine Arts & 4.28 & 1.89 & 5.22 & 1.87 & $.001^{* *}$ \\
\hline Math/Science & 6.03 & 1.83 & 7.1 & 1.73 & \\
\hline
\end{tabular}

* Cannot Reject $\mathrm{Ho}_{3} @ \square=.05$ level.

**Reject $\mathrm{Ho}_{3} @ \square=.05$ level

\section{Knowledge of Business Subjects}

Table 9 shows that there were no significant differences noted between the RSA Black and RSA White participants in the Business Administration component of the General Knowledge Test.

Table 9

Business Subjects Knowledge - RSA Blacks and RSA Whites

\begin{tabular}{|c|c|c|c|c|c|}
\hline & \multicolumn{2}{|c|}{ RSA Blacks } & \multicolumn{2}{|c|}{ RSA Whites } & \multirow[b]{2}{*}{ p-Value } \\
\hline $\begin{array}{c}\text { Business Sub- } \\
\text { jects }\end{array}$ & $\begin{array}{c}\text { Sample } \\
\text { Mean }\end{array}$ & $\begin{array}{l}\text { Standard } \\
\text { Deviation }\end{array}$ & $\begin{array}{c}\text { Sample } \\
\text { Mean }\end{array}$ & $\begin{array}{l}\text { Standard } \\
\text { Deviation }\end{array}$ & \\
\hline Accounting & 7.96 & 1.37 & 7.57 & 1.51 & $.241^{*}$ \\
\hline Economics & 8.22 & 1.58 & 7.67 & 1.72 & $.154 *$ \\
\hline Finance & 8.3 & 1.38 & 8.01 & 1.49 & $.401 *$ \\
\hline Management & 6.04 & 1.87 & 6.46 & 1.8 & $.307 *$ \\
\hline Marketing & 5 & 1.52 & 5.13 & 1.72 & $.725 *$ \\
\hline
\end{tabular}

* Cannot Reject $\mathrm{Ho}_{1} @ \square=.05$ level.

** Reject Ho $\mathrm{Ho}_{1} @ \square=.05$ level

Like the data in Table 9, Table 10 also shows that there were no significant differences noted between the USA Black and USA White participants in the Business Administration component of the General Knowledge Test. 
Table 10

Business Subjects Knowledge - USA Blacks and USA Whites

\begin{tabular}{|l|c|c|c|c|c|}
\cline { 2 - 5 } \multicolumn{1}{c|}{} & \multicolumn{2}{c|}{ USA Blacks } & \multicolumn{2}{c|}{ USA Whites } & \multirow{2}{*}{ p-Value } \\
\hline $\begin{array}{c}\text { Business Sub- } \\
\text { jects }\end{array}$ & $\begin{array}{c}\text { Sample } \\
\text { Mean }\end{array}$ & $\begin{array}{c}\text { Standard } \\
\text { Deviation }\end{array}$ & $\begin{array}{c}\text { Sample } \\
\text { Mean }\end{array}$ & $\begin{array}{c}\text { Standard } \\
\text { Deviation }\end{array}$ & $.093 *$ \\
\hline Accounting & 5.56 & 5.24 & 6.68 & 2.21 & $.196 *$ \\
\hline Economics & 6.67 & 2.4 & 7.39 & 1.55 & $.202 *$ \\
\hline Finance & 6.22 & 0.97 & 6.99 & 1.78 & $.432 *$ \\
\hline Management & 5.67 & 1.32 & 6.15 & 1.82 & $.389 *$ \\
\hline Marketing & 5.11 & 1.17 & 5.59 & 1.64 & \\
\hline
\end{tabular}

* Cannot Reject $\mathrm{Ho}_{2} @ \square=.05$ level.

** Reject $\mathrm{Ho}_{2} @ \square=.05$ level

Table 11 shows the statistical data derived when combining the scores achieved by all RSA and USA Blacks who took the Business Subjects component of the General Knowledge Test and then contrasting them with that of all RSA and USA Whites who took the test. The result of these combinations, reflected in the p-Values, shows that there were no significant differences noted in any of the five business subjects for Blacks and Whites.

Table 11

Business Subjects Knowledge -- Contrasting the Combination of RSA and USA Blacks With the Combination of RSA and USA Whites

\begin{tabular}{|c|c|c|c|c|c|}
\hline \multirow[b]{3}{*}{$\begin{array}{l}\text { Business Sub- } \\
\text { jects }\end{array}$} & \multicolumn{4}{|c|}{ es } & \multirow[b]{3}{*}{ p-Value } \\
\hline & \multicolumn{2}{|c|}{$\begin{array}{c}\text { Combination of } \\
\text { RSA and USA Blacks }\end{array}$} & \multicolumn{2}{|c|}{$\begin{array}{c}\text { Combination of } \\
\text { RSA and USA Whites }\end{array}$} & \\
\hline & $\begin{array}{c}\text { Sample } \\
\text { Mean }\end{array}$ & $\begin{array}{l}\text { Standard } \\
\text { Deviation }\end{array}$ & $\begin{array}{c}\text { Sample } \\
\text { Mean }\end{array}$ & $\begin{array}{l}\text { Standard } \\
\text { Deviation }\end{array}$ & \\
\hline Accounting & 7.36 & 2.22 & 7.11 & 2.03 & $.497 *$ \\
\hline Economics & 7.83 & 1.9 & 7.48 & 1.61 & $.240 *$ \\
\hline Finance & 7.78 & 1.57 & 7.33 & 1.75 & $.152 *$ \\
\hline Management & 5.94 & 1.74 & 6.25 & 1.81 & $.341 *$ \\
\hline Marketing & 5.03 & 1.42 & 5.44 & 1.68 & $.165 *$ \\
\hline
\end{tabular}

* Cannot Reject $\mathrm{Ho}_{3} @ \square=.05$ level.

** Reject $\mathrm{Ho}_{3} @, \square=.05$ level

\section{Conclusions}

If it is true that one of the fundamental goals of a nation's educational system is to deliver the wisdom of the ages to successive generations; then it has the responsibility to assess how well it is accomplishing its task. In higher education, professors assess the learning of their students using examinations, tests, projects, analyses, hands-on experiments, etc. If a higher education system determines that one group of students on average does better than another group, higher education has the responsibility to first identify where disparities occur, and second, determine their strength. Thereafter, higher education should investigate possible causal links and initiate sound educational policy prescriptions to eliminate such disparities.

Cataloguing knowledge disparities is easier said than done in a climate of "political correctness" (p.c.) where higher education institutions informally declare that such comparisons are taboo. This certainly seems to be the case when trying to discuss issues dealing with racial comparisons. But, there is a great deal of evidence that a disparity exists according to the U.S. Department of Education, the College Board, American Council on Education, the National Center of Education Statistics, etc. The combination of these organizations recognize that there are disparities between the average scores achieved by American White and Black students in their general knowledge of mathematics, science, history, geography, reading, advanced placement tests and scholastic achievement tests (see Introduction, above). Ignoring what is considered p.c., the body of evidence of this disparity should motivate institu- 
tions of higher learning to ask: Is this disparity universal? Is it found in other nations that are historically similarly situated to the U.S.? The present study sought to answer these questions. Several conclusions have been reached as a result of this study:

1. Of the five Liberal Arts areas tested, South African Blacks scored significantly better than their White counterparts in Current Affairs. RSA Whites, however, scored significantly better in Literature/Fine Arts and Math/Science. There were no significant differences in Geography and History.

2. Similarly, of the five Liberal Arts areas, USA Whites scored significantly better than there Black counterparts in Geography, and Math/Science. There were, however, no significant differences noted in Current Affairs, History, and Literature/Fine Arts.

3. When combining the scores achieved in the Liberal Arts portion of the General Knowledge Test by all RSA and USA Blacks, and contrasting them with those of all RSA and USA Whites, it was found that Blacks outperformed Whites in Current Affairs. Whites, however, outperformed Blacks in Literature/Fine Arts and Math/Science. There were no significant differences noted in Geography and History.

4. Out of the five Business Subjects tested, there were no significant differences noted in any area for RSA Blacks and Whites. The same result was found when comparing the statistics of the USA Blacks and Whites - that is, there was no significant differences noted in any of the five business subjects.

5. When the combining the Business Subjects' scores achieved by all of the Black and White participants from both countries, there were no significant differences noted.

Given the above summarized findings, the central point derived from this study is that whereas there are a few differences noted between the general knowledge in liberal arts topics between the Blacks and Whites of the RSA and the USA, the overall knowledge of the two groups are very close. That is, while one racial group may score higher in one area, the other group may score higher in another. With respect to knowledge of business administration subjects, no differences were noted. Thus, from this study, higher education stakeholders can exude confidence that it does not appear that Black or White students are getting short-changed when it comes to the knowledge that they are gleaning from their educational experiences.

\section{Recommendations For Further Study}

It would be interesting to see if the findings obtained in this study could be replicated in other studies whose research methods included a larger sample size, different colleges/universities and from other geographical regions. Incorporation of these recommendations into a future study may point to remedies needed to address disparities among groups.

\section{References}

1. ACT Media Relations. (2000). 2000 National and State Scores: Selections from the 2000 National Score Report.

2. The American Heritage Dictionary. (1976). (Boston: Houghton Mifflin Company, William Morris, ed.)

3. Campbell, Jay R., Voelkl, Kristin E. \& Donahue, Patricia L. (1997). Report in Brief: NAEP 1996 Trends in Academic Progress, National Center for Education Statistics. (1996). Document can be found on the Internet at <http://nces.ed.gov/naep/96report/97986.shtml>.

4. The College Board. (1999). Profile of College-Bound Seniors - National Report.

5. The College Board, Advanced Placement Program. (1996). National Summary Reports, various years. <http://nces.ed.gov/pubs/ce/c9718a01.html>

6. The Condition of Education, Indicator 19. (1996). Average Geography Proficiency of $4^{\text {th }}$-, $8^{\text {th }}$-, and $12^{\text {th }}$-graders, U.S. Department of Education, National Center for Education Statistics. Document can be found on the Internet at <http://nces.ed.gov.pubs.ce/c9619a01.html>.

7. Jencks, Christopher and Phillips, Meredith. (1998). The Black-White Test Score Gap, Brooking Institution Press, and published on the Internet by The New York Times Company, and can be found on the Internet at <http://www.nytimes.com/books/first/j/jencks-gap.html>.

8. U.S. Department of Education, National Center for Education Statistics (1998). NAEP 1998 Reading, A Report Card for the nation and the States.

9. U.S. Department of Education, National Center for Education Statistics. (1997). NAEP 1996 Mathematics Report Card for the Nation and the States: Findings from the National Assessment of Educational Progress. 